\title{
A MODIS-Derived Value-Added Climatology of Maritime Cloud Liquid Water Path That Conserves Solar Reflectance ${ }^{\mathscr{O}}$
}

\author{
AmAnda Gumber And Michael J. Foster \\ Space Science and Engineering Center, University of Wisconsin-Madison, Madison, Wisconsin
}

(Manuscript received 11 July 2016, in final form 26 February 2017)

\begin{abstract}
A dataset is generated from a method to retrieve distributions of cloud liquid water path over partially cloudy scenes. The method was introduced in a 2011 paper by Foster and coauthors that described the theory and provided test cases. Here it has been applied to Moderate Resolution Imaging Spectroradiometer (MODIS) collection-5 and collection-6 cloud products, resulting in a value-added dataset that contains adjusted distributions of cloud liquid water path for more than 10 years for marine liquid cloud for both Aqua and Terra. This method adjusts horizontal distributions of cloud optical properties to be more consistent with observed visible reflectance and is especially useful in areas where cloud optical retrievals fail or are considered to be of low quality. Potential uses of this dataset include validation of climate and radiative transfer models and facilitation of studies that intercompare satellite records. Results show that the fit method is able to reduce bias between observed visible reflectance and that derived from optical retrievals by up to an average improvement of $3 \%$. The level of improvement is dependent on several factors, including seasonality, viewing geometry, cloud fraction, and cloud heterogeneity. Applications of this dataset are explored through a satellite intercomparison with PATMOS-x and Global Change Observation Mission-First Water (GCOM-W1; "SHIZUKU") AMSR-2 and use of a Monte Carlo radiative transfer model. From the 3D Monte Carlo model simulations, albedo biases are found when the method is applied, with seasonal averages that range over 0.02-0.06.
\end{abstract}

\section{Introduction}

Cloud feedbacks remain a major source of uncertainty for climate sensitivity in general circulation models (GCM). One of the leading sources of this uncertainty is variability in solar radiation from changes in low-level marine cloud processes, which include shallow cumulus and stratocumulus-topped boundary layer clouds (Webb et al. 2013). These clouds cover a vast amount of Earth's oceans, giving them an important role in regulating Earth's energy budget, especially with respect to incident solar radiation. Approximately $30 \%$ of incoming solar radiation is reflected back to space from these clouds, which causes an overall net cooling effect at the surface. With continual progress still being made, studies have found that the variability of the solar radiative field in GCMs can be attributed to poor

Supplemental information related to this paper is available at the Journals Online website: http://dx.doi.org/10.1175/ JAMC-D-16-0241.s1.

Corresponding author: Amanda Gumber, gumber@wisc.edu simulation of clouds, including the neglect of subgridscale processes and cloud morphology (Cahalan et al. 1994b; Pincus and Klein 2000; Larson et al. 2001; Barker et al. 2003, 2016; Bogenschutz and Krueger 2013; Herwehe et al. 2014; Xiao et al. 2014).

To obtain computationally efficient global-model runs, some GCMs simplify the radiative transfer to one vertical dimension, giving clouds and their boundary conditions a one-dimensional (1D) plane-parallel assumption. Often, cloud properties and atmospheric conditions are based on mean values within the grid cell. Given that the horizontal resolution of commonly used GCMs ranges from 100 to $200 \mathrm{~km}$, the variability of incloud properties must be parameterized to fit the much larger grid cell (IPCC 2013). Studies using large-eddy simulations (LES) of marine boundary layer clouds have shown that cloud properties such as cloud liquid water path are sensitive to changes at horizontal resolutions of $100 \mathrm{~m}$ (Siebesma et al. 2003; Stevens et al. 2005; Shonk et al. 2012). The microphysical properties of clouds remain an important part of research since aspects of cloud microphysical processes are still poorly understood. With respect to using GCMs for climate projections, a 
misrepresentation of cloud microphysical properties can lead to errors in atmospheric heating rates, cloud formation and dissipation, and precipitation rates.

The objective of quantifying the magnitude of the bias in GCMs caused by the treatment of clouds as homogeneous is the focus of many studies. These studies typically address either the effects of the in-cloud distributions of properties or the external cloud morphology. The bias caused from the neglect of in-cloud microphysical properties is referred to as the plane-parallel albedo bias. The plane-parallel albedo bias is calculated as the difference between the independent column approximation (ICA) and the standard 1D plane-parallel calculations (Cahalan et al. 1994b). The ICA calculation consists of dividing a given grid cell into several vertical columns and calculating the individual cloud properties for each smaller grid cell. This approximation accounts for internal cloud heterogeneity. A variety of studies have been conducted to quantify the effects of the plane-parallel albedo bias within models (Cahalan et al. 1994a; Marshak et al. 1998; Barker et al. 1999; Di Giuseppe and Tompkins 2003, 2005; Oreopoulos et al. 2004; Räisänen et al. 2004; Barker and Räisänen 2005). The results of the impacts of the planeparallel albedo bias vary from study to study given the use of different types of cloud-generating models such as an LES or a cloud-resolving model and different cloud types. Studies have also been conducted examining this bias with satellite data (Barker et al. 1996; Oreopoulos and Davies 1998; Pincus et al. 1999; Fu et al. 2000; Oreopoulos et al. 2007; Zhang et al. 2012). Most important is that certain studies looked at the plane-parallel bias for marine stratocumulus clouds, which most closely resemble a planeparallel assumption (Cahalan et al. 1994a,b). The results showed that even stratocumulus clouds are affected by this bias. The ICA method is able to capture the bias caused by the neglect of in-cloud properties, but it does not account for horizontal photon transport between grid cells.

Throughout the range of these studies, satellite observations have been increasingly incorporated into radiative transfer simulations since they more accurately portray cloud scenes and provide global data from multiple instruments. Satellite observations are used to identify cloud microphysical properties as well as to provide a relationship between clouds and their radiative properties. Satellite instruments provide the only record of long-term global cloud observations that can provide validation for models. Satellite records experience their own set of issues, however. Similar to GCMs, satellite retrieval algorithms often use $1 \mathrm{D}$ radiative transfer for solving the inverse problem of satellite remote sensing. This approach causes errors in retrieving cloud optical properties such as optical depth and particle size. Some instruments, such as the Moderate Resolution Imaging
Spectroradiometer (MODIS) instrument, rely on opticaldepth retrievals and particle size to calculate liquid water path (Seethala and Horváth 2010). In addition, distributions of satellite-derived cloud properties can be skewed depending on the quality-assurance procedures that are implemented in the retrieval process. For example, MODIS uses a cloud mask to determine which pixels are considered to be cloudy (Ackerman et al. 1998, 2010). From this, an algorithm called clear-sky restoral (CSR) is used to perform a series of quality checks to determine whether cloud-property retrieval will be made for a specific pixel (King et al. 2006). Although the CSR algorithm provides a filter for pixels that would be poor candidates for retrievals, it tends to preferentially remove those that are optically thin and/or are located at the edges of clouds, which affects the distributions of cloud properties. The MODIS collection-5 cloud product denotes these pixels as failed retrievals, whereas MODIS collection- 6 contains a separate retrieved variable for pixels for which the CSR indicates that they are classified as cloud-edge or inhomogeneous/partially cloudy pixels (Cho et al. 2015).

An objective of this study is to address the issues described above by providing an improved record of MODIS-observed cloud properties suitable for validation of climate or radiative transfer models that minimizes biases introduced by failed/missing retrievals and takes into account the nonlinear nature of cloud optical properties. To do this, a method introduced in Foster et al. (2011) is used that creates horizontal distributions of liquid cloud properties over a given area while conserving the total-scene observed visible reflectance. This method is applied to the MODIS record for both Aqua and Terra from $60^{\circ} \mathrm{N}$ to $60^{\circ} \mathrm{S}$ for marine liquid clouds for a $1^{\circ} \times 1^{\circ}$ scale. In section 2 , the data used in this study are described as well as the method from Foster et al. (2011) that was used to create the horizontal distributions of liquid cloud properties. In section 3, the method is evaluated over the MODIS record with respect to the adjustments in the liquid cloud properties, recreation of the scene visible reflectance, variable dependencies, and validation including microwave data. In section 4 , the applications of the fit method are explored through a satellite intercomparison using PATMOS-x and a 3D radiative transfer model. In section 5 , conclusions and future work will be discussed.

\section{Data and methods}

\section{a. Data}

\section{1) MODIS}

The MODIS instrument is located on the polar-orbiting satellites Aqua and Terra, containing 36 spectral bands 
that range over $0.4-14.4 \mu \mathrm{m}$ with spatial resolutions varying from $250 \mathrm{~m}$ to $1 \mathrm{~km}$, depending on the selected band. MODIS has been aboard Terra since 1999 and aboard Aqua since 2002. Used in this study is the MODIS Atmosphere Level 2 Joint Product (MY/ODATML2), which contains cloud, cloud-mask, atmospheric-profile, aerosol, and water vapor products. Both collection 5 and collection 6 are examined here.

The relevant products come from the cloud and cloud-mask products. The MODIS Cloud Mask Product (MY/OD35) uses an algorithm that employs a series of tests with visible and infrared thresholds (Ackerman et al. 1998, 2010). From this series, confidence levels are assigned to each pixel, with the broadest categories specifying confident clear, probably clear, probably cloudy, and cloudy. The cloud mask is used to determine cloudy pixels and cloud fraction over an area. The MODIS Cloud Product (MY/OD06) combines both visible and infrared radiances to solve for radiative and physical cloud properties. As used in this study, cloud optical thickness, liquid water path, effective radius, and cloud particle phase are derived from the visible, near-infrared, and shortwave infrared bands. Cloud-top temperature and pressure are retrieved from the infrared bands (King et al. 1997). A detailed guide that explains the major updates between collection 5 and collection 6 for MY/OD06 is given by Platnick et al. (2015).

The clear-sky restoral algorithm identifies cloudy pixels to retrieve optical and microphysical properties of clouds. The MODIS cloud-mask product has certain pixels that are classified as probably cloudy and probably clear. The clear-sky restoral algorithm identifies whether those pixels would be poor retrieval candidates. If the algorithm finds the pixel to be a poor candidate, no retrieval of optical and microphysical properties is made. This can happen for instances of dust or smoke, snow or ice surfaces, and sun glint as well as for cloudedge pixels and pixels identified as highly inhomogeneous at the 250-m subpixel level (King et al. 2006). In collection 5, cloud properties were not retrieved for these pixels and were given missing values regardless of successful retrieval in the cloud-property algorithm. In collection 6, a separate dataset referred to as "partly cloudy" (PCL) is created for successful retrievals of the cloud-property algorithm for which the CSR algorithm has marked the pixels as cloud edges or inhomogeneous (Cho et al. 2015).

The MODIS Level 1B Subset Calibrated Geolocation Dataset (MY/OD02SSH) is used in combination with the joint-atmosphere product. This dataset is sampled from the MODIS level-1B 1-km data. The data are sampled at $0.1^{\circ}$ and later separated into $1^{\circ} \times 1^{\circ}$ areas to create a level-2B product.

\section{2) PATMOS-X}

The PATMOS-x dataset contains atmospheric and surface products from the AVHRR instrument, which has been aboard NOAA meteorological satellites since 1979 (Heidinger et al. 2014). The instrument has six spectral bands that range from solar to terrestrial infrared. The cloud mask is defined by employing a Bayesian algorithm using collocated Cloud-Aerosol Lidar and Infrared Pathfinder Satellite Observations (CALIPSO) data. PATMOS-x is processed using global area coverage (GAC) data with a resolution of approximately $1 \mathrm{~km} \times 4 \mathrm{~km}$. A level-2B product is created from sampling the GAC data using the closest pixel in relation to a $0.1^{\circ} \times 0.1^{\circ}$ grid. These data are hosted at the NOAA National Centers for Environmental Information. PATMOS-x has the ability to process other satellite datasets, such as MODIS data.

\section{3) AMSR-2}

The Advanced Microwave Scanning Radiometer 2 (AMSR-2) is on board the Global Change Observation Mission-First Water (GCOM-W1; "SHIZUKU") satellite, which replaced the Advanced Microwave Scanning Radiometer for Earth Observing System (AMSR-E) aboard Aqua in 2012. For this study, a year of gridded daily GCOM-W1 level-3 data from the Japan Aerospace Exploration Agency (JAXA) GCOM-W1 Data Providing Service (https://gcom-w1.jaxa.jp/) were used. The level-3 product used is the cloud liquid water path globally averaged on a $0.1^{\circ} \times 0.1^{\circ}$ grid to match the MODIS data.

\section{b. Methods}

\section{1) HORIZONTAL DISTRIBUTIONS OF CLOUD PROPERTIES CONSERVING SCENE VISIBLE REFLECTANCE}

This method uses MODIS satellite measurements to calculate liquid cloud properties over partially cloudy scenes while conserving the total-scene reflectance (Foster et al. 2011). The ocean from $60^{\circ} \mathrm{N}$ to $60^{\circ} \mathrm{S}$ is studied using MODIS data. Ice clouds are filtered out. The ocean regions are chosen because the variability of surface emissivity over ocean is less than that over land. Many of the equations for the fit method rely on relationships with reflectivity values that are sensitive to variations of the surface albedo. Horizontal distributions of liquid water path will be generated using the successful retrievals from MODIS (mask method) and derived distributions using a fit function between optical depth and visible reflectance (fit method) over a $1^{\circ} \times 1^{\circ}$ area. 


\section{(i) Mask method}

The mask method refers to using the successful cloudproperty retrievals made by the MODIS algorithms. The mask method obtains its cloudy pixels from the cloud mask. Pixels that have liquid water path retrievals are used to create a distribution. Cloud fraction is calculated from the ratio of pixels with liquid water path retrievals to the total number of pixels within the $1^{\circ} \times 1^{\circ}$ area.

\section{(ii) Fit method}

The fit method refers to the method published in Foster et al. (2011) that aims to include the neglected optical retrievals from thin clouds and cloud-edge pixels. The horizontal distributions are generated with respect to liquid water path. This method can also be used to create horizontal distributions of other cloud properties such as cloud optical depth and cloud effective radius. The focus of this study is liquid water path.

Different from the mask method, the fit method calculates liquid water path on the basis of a relationship between cloud optical depth and visible reflectance over a $1^{\circ} \times 1^{\circ}$ area where pixels have been sampled at $0.1^{\circ}$. From the valid retrievals of cloud optical depth in the original dataset, the relationship between the visible reflectance $R_{\text {vis }}$ and retrieved optical depth $\tau_{\text {ret }}$ can be seen as the following, where $a, b$, and $c$ are coefficients that account for directional dependence from solar zenith angle, single-scattering albedo, and asymmetry parameters as well as geometric series that account for multiple-scattering effects between the cloud and surface (Koren et al. 2008; Foster et al. 2011):

$$
R_{\mathrm{vis}}+\frac{c\left(1-R_{\mathrm{vis}}\right)^{2}}{1-c R_{\mathrm{vis}}}=\frac{a \tau_{\mathrm{ret}}}{1+b \tau_{\mathrm{ret}}} .
$$

Next, the equation can be solved with respect to cloud optical depth $\tau_{\text {ret }}$. Values of cloud optical depth are then calculated for the entire scene. A different equation must be used to solve for liquid water path because effective-radius values are not available for each calculated value of cloud optical depth. Using equations from Bennartz (2007), liquid water path is calculated using droplet number concentration, condensation rate, and cloud optical depth. Condensation rate is calculated from the following Eq. (2), where

$$
\frac{d e_{\mathrm{sat}}(T)}{d T} \frac{d T}{d z}
$$

is the derivative of the saturation vapor pressure with respect to temperature and saturated adiabatic lapse rate for an adiabatically ascending parcel. Here, $R_{\mathrm{H}_{2} \mathrm{O}}$ is the gas constant for water vapor. The condensation rate is calculated at $80 \%$ of the adiabatic value assuming the adiabatic ascent of an air parcel and the condensation of water exceeding saturation:

$$
c_{w}=0.8 \frac{1}{R_{\mathrm{H}_{2} \mathrm{O}} T} \frac{d e_{\mathrm{sat}}(T)}{d T} \frac{d T}{d z} .
$$

Equation (3) calculates droplet number concentration, where $k$ is the ratio between the liquid-droplet volume-mean radius and the effective radius to the third power and $Q$ is the extinction efficiency. The term CF denotes cloud fraction. Droplet number concentrations and condensation rate are averaged over the scene and are considered to be constants when calculating the individual pixel liquid water path:

$$
N=\frac{2^{-5 / 2}}{k} \tau^{3}\left(\frac{W}{\mathrm{CF}}\right)^{-5 / 2}\left(\frac{3}{5} Q \pi\right)^{-3}\left(\frac{3}{4 \pi \rho_{L}}\right)^{-2} c_{w}^{1 / 2} .
$$

The droplet number concentration is considered to be constant relative to the size of the spatial domain. Equation (3) can then be solved for liquid water path as seen in Eq. (4). When using this equation to denote a single value of liquid water path, $\mathrm{CF}$ is assumed to be 1 . Extinction efficiency $Q$ is approximately 2 for visible light, and $k$ is estimated at a constant value of 0.8 (Lu and Seinfeld 2006):

$$
W=\left[\frac{2^{-5 / 2}}{k} \frac{\tau_{\mathrm{fit}}^{3}}{N}\left(\frac{3}{5} Q \pi\right)^{-3}\left(\frac{3}{4 \pi \rho_{L}}\right)^{-2} c_{w}^{1 / 2}\right]^{2 / 5} .
$$

At this point, there is a measurement of liquid water path for every observed visible reflectance, meaning there are values for both clear sky and cloudy sky. Assuming a Gaussian distribution of clear-sky reflectance, the clear sky can be subtracted from the totalsky reflectance distribution. The center of the clear-sky distribution is defined as the median of the clear-sky reflectance values determined by the cloud mask. To create the distribution of liquid water path, the clear-sky reflectance is converted to optical depth using the relationship of optical depth and visible reflectance established in Eq. (1). The values of clear-sky optical depth are subtracted from the fit method-derived totalsky values of optical depth, and the values of cloudy-sky optical depth can be converted to liquid water path as described in Eq. (4) for a calculation of a distribution of cloudy-sky liquid water path. The cloud fraction is solved using a ratio of the number of clear-sky pixels from the symmetric distribution divided by the number of pixels in the total-scene reflectance and subtracting from the total distribution. 


\section{(iii) PDFs of liquid water path}

Statistical moments of liquid water path produced for the mask and fit methods are used to create probability distribution functions (PDF) to identify the horizontal distribution and probability of occurrence for each scene. A gamma function or a Gaussian function can be applied for these distributions. Because the gamma function performed better in Foster et al. (2011), it is used in this study. The gamma function is the following from Heidinger (2003), where $\nu$ is the width parameter:

$$
\operatorname{PDF}(W)=\frac{1}{\Gamma(\nu)}\left(\frac{\nu}{\bar{W}}\right)^{\nu} W^{\nu-1} e^{-(W \nu / \bar{W})} .
$$

\section{(iv) Total-scene reflectance calculation}

The total-scene reflectance is calculated by using the cloud fraction, the mean reflectance of the cloudy portion, and the mean reflectance of the clear portion [Eq. (6)]. Here, $\mathrm{CF}$ is the cloud fraction calculated for each method over the $1^{\circ} \times 1^{\circ}$ area:

$$
\overline{R_{\text {tot }}}=\mathrm{CF}\left(\overline{R_{\mathrm{cld}}}\right)+(1-\mathrm{CF})\left(\overline{R_{\mathrm{clr}}}\right) \text {. }
$$

The mean reflectance for the clear sky $\overline{R_{\mathrm{clr}}}$ is the mean of the clear pixel defined by the cloud mask. The mean reflectance for the cloudy portion of the sky $\overline{R_{\mathrm{cld}}}$ is determined by converting the PDF of liquid water path into a PDF of visible reflectance [Eq. (7)]. This is done by converting the PDF of liquid water path back to a PDF of optical depth using Eq. (4). The distribution of cloud optical depth is converted back to reflectivity, and the mean of this distribution is used to solve the mean visible reflectance for the cloudy part of the sky:

$$
\overline{R_{\mathrm{cld}}}=\int_{0}^{\infty} R_{\mathrm{vis}} \operatorname{PDF}(W) d W .
$$

\section{2) RADiATIVE TRANSFER SIMULATION}

The application of the fit method is explored through the use of a $3 \mathrm{D}$ radiative transfer model. Using the derived distributions of liquid water path, the Intercomparison of 3D Radiation Codes (I3RC) community Monte Carlo model (Cahalan et al. 2005; Pincus and Evans 2009) runs simulations to recreate the top-ofatmosphere albedo. The top-of-atmosphere albedo is compared with the visible reflectance directly observed by MODIS, and therefore the radiative transfer is performed over the wavelengths $620-670 \mathrm{~nm}$, which is the interval for band 1 of MODIS. The gaseous absorption and aerosols are neglected in the simulations.

The scattering properties are calculated using Mie theory to create a phase-function table as a function of effective radius for a distribution of spherical particles. The particles are identified as water, ice, or aerosols. For the purpose of applying the fit method to $3 \mathrm{D}$ radiative transfer, the only particles included are water particles since ice clouds are screened out from the analysis. The program calculates the phase-function table along with extinction and single-scattering albedo of the particles.

For each 3D simulation, the $1^{\circ} \times 1^{\circ}$ domain is employed with a sampling of $0.1^{\circ} \times 0.1^{\circ}$, where each grid cell is considered either fully cloudy or clear. The surface albedo is 0.06 given that all scenes are over the ocean. The height and temperature profiles are from the MODIS Atmospheric Profile Product (MY/OD07_L2), which is retrieved for 20 vertical levels. The 3D scene is constructed from the MODIS cloud product. The geometric thickness of the cloud is calculated using liquid water path and condensation rate and is placed on the basis of the cloud-top-height variable (Bennartz 2007). If there is no cloud-top height available for a measurement of liquid water path, the height is estimated from the mean of the cloud-top heights that are available in the scene. Two separate scenes are created using the values of liquid water path supplied by both the fit method and the mask method. The height and temperature profiles are a daily average over the specified ocean domain.

\section{Results}

\section{a. Assessment of the mask and fit methods}

Using the fit and mask methods, horizontal distributions of liquid cloud properties are generated for $1^{\circ} \times 1^{\circ}$ areas over the ocean from $60^{\circ} \mathrm{N}$ to $60^{\circ} \mathrm{S}$ during $2003-14$ for both Aqua and Terra. Results from Foster et al. (2011) show that, for many cases, the statistical moments generated by the fit method create liquid water path distributions that more closely conserve cloud amount and total-scene reflectance when compared with methods that generate distributions only using valid liquid water path retrievals. Recreating scene visible reflectance assesses the validity of these distributions. The ability to reconstruct the scene visible reflectance is due to the relationship between cloud optical properties and radiances in models. One way a GCM or radiative transfer model may be evaluated is simulating top-ofatmosphere or surface radiances and comparing them with the observed reflectance from satellite data. Biases in the distribution of cloud properties will affect the model's capacity to reproduce the observed data. The method was applied to MODIS collection 5, collection 6, and collection 6 including the PCL retrievals. Datasets are generated for both Aqua and Terra; because of the similarities between the two datasets, only the results from Aqua will be shown for brevity. The corresponding 


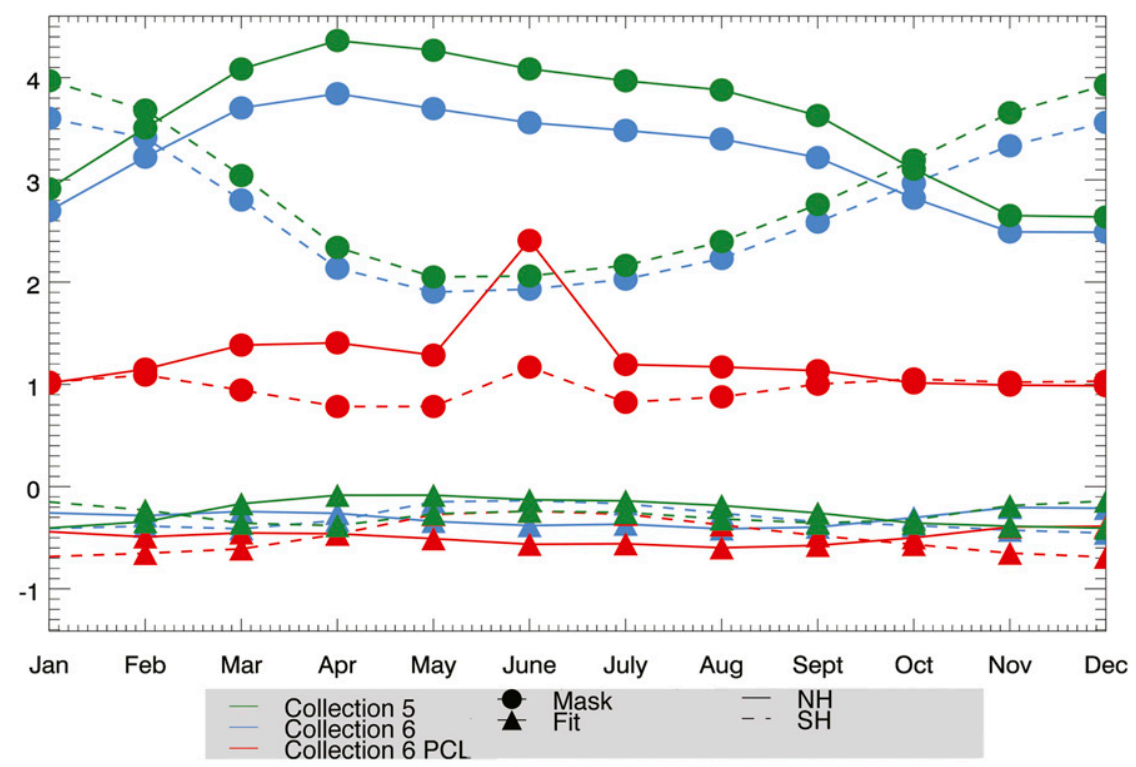

FIG. 1. Average monthly bias between derived and observed reflectance for the mask (circle) and fit (triangle) methods for the Northern Hemisphere (solid) and Southern Hemisphere (dashed) for collection 5 (green), collection 6 (blue), and collection 6 PCL (red) for Aqua from 2003 to 2014.

results from Terra can be found in the online supplemental material.

After applying both the fit and mask methods to 11 years of Aqua MODIS data, the percentage bias is shown for monthly hemispheric averages in Fig. 1. The percentage bias is defined as the difference between the derived and observed reflectance. Most notable is that a seasonal cycle is shown for the mask method using collection 5 and collection 6 . The mask method shows a positive bias, with the largest bias in the respective summer months for each hemisphere. Collection 5 shows a larger bias using the mask method than does collection 6 . For collection 6 including PCL pixels, the bias from the mask method is considerably reduced and there is a dampening of the seasonal cycle. The mask method continually overestimates the observed scene visible reflectance, with a positive bias ranging from $0.75 \%$ to $4.5 \%$. A seasonal cycle for the average of monthly bias of the fit method is nonexistent, with the average bias reaching very close to zero for both satellites and hemispheres. The fit method bias ranges from $-0.9 \%$ to $0.3 \%$. The collection- 5 data benefit most from using the fit method, with the lowest amount of bias for recreating the scene visible reflectance. The collection- 6 data including PCL pixels show the largest negative bias of all three datasets from using the fit method. Although it shows this underestimation in recreating the scene visible reflectance, the fit method still creates a smaller difference than the mask method does.
Terra shows a slightly smaller bias in comparison with Aqua for both the mask and the fit methods. This could possibly be linked to the cloud amounts present during the satellite overpass time. A study from King et al. (2013) reviewing the spatial and temporal distributions of clouds observed by both Aqua and Terra showed that the oceans tend to be cloudier during Terra's earlier overpass. With more cloud pixels detected, the fit method is likely to create a better fit function between the observed visible reflectance and retrieved optical depth measurements.

From these results, the fit method can be seen as an overall improvement relative to the mask method. The analysis was expanded globally to determine which areas experience the greatest benefit from the fit method. Figure 2 shows the mask bias, the fit bias, and the percentage improvement between the biases of the mask and fit methods. The percentage improvement is calculated as the absolute difference between the biases of the fit and mask methods. Positive values indicate that the fit method shows a smaller bias than the mask method, and negative values indicate cases in which the mask method shows a smaller bias than the fit method. The mask bias steadily decreases from collection 5 to collection 6 PCL, with consistent overestimation. Maskmethod bias for collection 5 and collection 6 is the largest along the equator, and the mask-method bias for collection 6 PCL shows only a small amount of overestimation in this region. The fit bias for all of the 

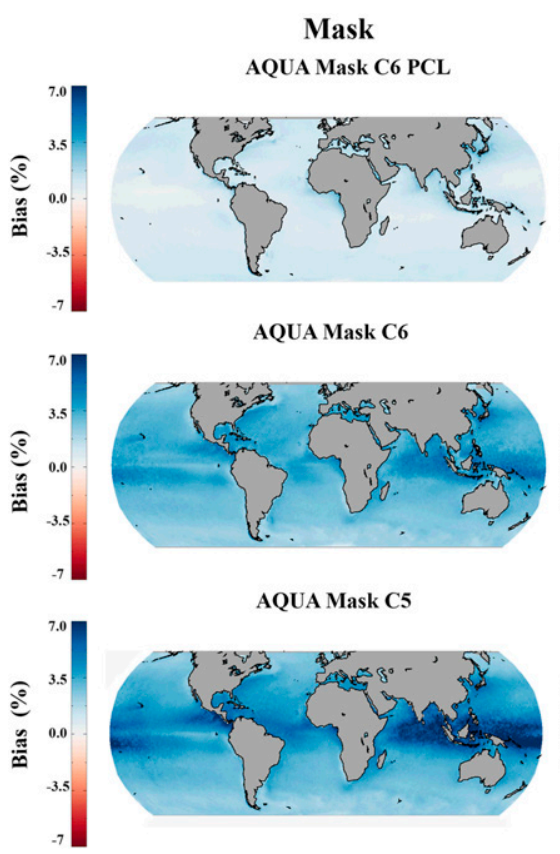
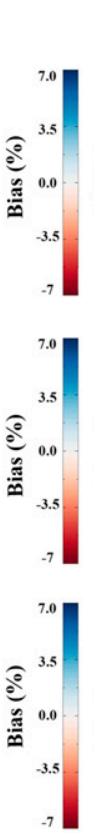

Fit

AQUA Fit C6 PCL

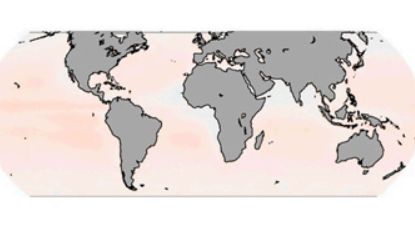

AQUA Fit C6

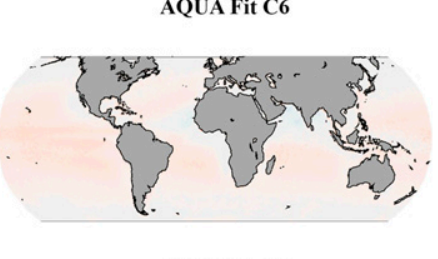

AQUA Fit C5

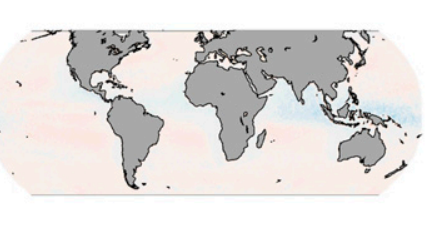

Percentage Improvement AQUA C6 PCL
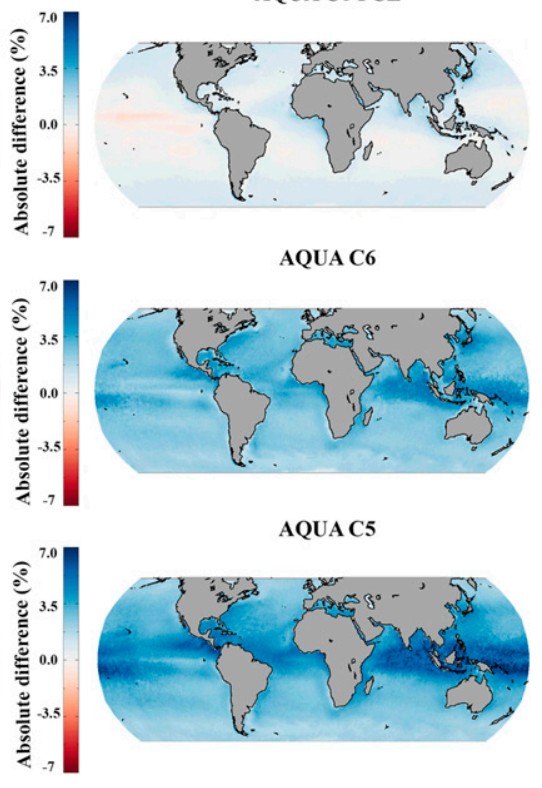

AQUA C6

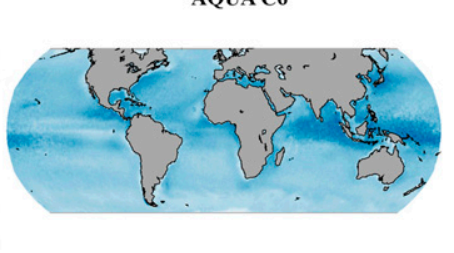

AQUA C5

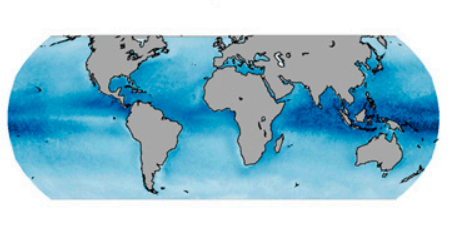

FIG. 2. Global maps displaying the difference between the derived and observed reflectance for the (left) mask and (center) fit methods and (right) the percentage improvement between the fit and mask methods for (top) collection 6 PCL, (middle) collection 6, and (bottom) collection 5 for Aqua from 2003 to 2014.

datasets is relatively similar, with the exception of collection 5 displaying a slight overestimation along the equator. Otherwise, the fit-method bias is marginally skewed toward underestimating the scene visible reflectance. For the percentage improvement, collection 5 shows the greatest improvements, with the largest over the tropics with maximum values reaching up to $7 \%$, especially for regions in the ITCZ that experience precipitation. The collection- 6 data spatially look similar to those of collection 5, but the percentage improvement decreases approximately $2 \%-3 \%$. With the inclusion of the PCL pixels, collection 6 only shows a small amount of improvement using the fit method, with the mask method performing slightly better around some regions in the tropics.

Overall, the inclusion of the partly cloudy pixels in collection 6 greatly improves the distributions derived from the mask method. This result shows that the missing edge pixels, optically thin clouds, and highly heterogeneous clouds are important when recreating the scene visible reflectance. The percentage of missing retrievals for each scene is calculated by the difference between the number of pixels identified as cloudy by the cloud mask and the number of liquid water path retrievals, which is then divided by the total number of pixels for each scene. Figure 3 shows the percentage of missing retrievals in comparison with the difference between the derived and observed reflectance for both the mask and fit methods for each dataset. The percentage of missing retrievals cannot surpass $80 \%$ since scenes with cloud fractions of less than 0.2 were filtered out. For the mask method, there is always an overestimation of the visible reflectance regardless of the missing number of retrievals for all datasets and satellites. As the percentage of missing retrievals increases, the bias between the derived and observed reflectance also increases. The mask bias for collection 6 including PCL pixels increases linearly as the number of missing retrievals increases. For the fit method, all datasets show an exponential decrease from $0 \%$ to $10 \%$ of missing retrievals. As the number of missing retrievals increases, the slight negative bias increases toward zero, indicating that the fit method restores the missing retrievals while maintaining the scene visible reflectance. The fit method shows more positive biases around $75 \%$ of missing retrievals.

The fit method remained relatively constant for each dataset, showing that the fit function used is able to maintain the relationship between the visible reflectance and cloud properties. Despite a few areas where there was no improvement using the collection 6 PCL dataset, the fit method displayed the ability to overall minimize bias and recreate the scene visible reflectance.

\section{b. Variable dependencies}

Although the fit method greatly reduces the amount of bias in recreating the scene visible reflectance, certain 


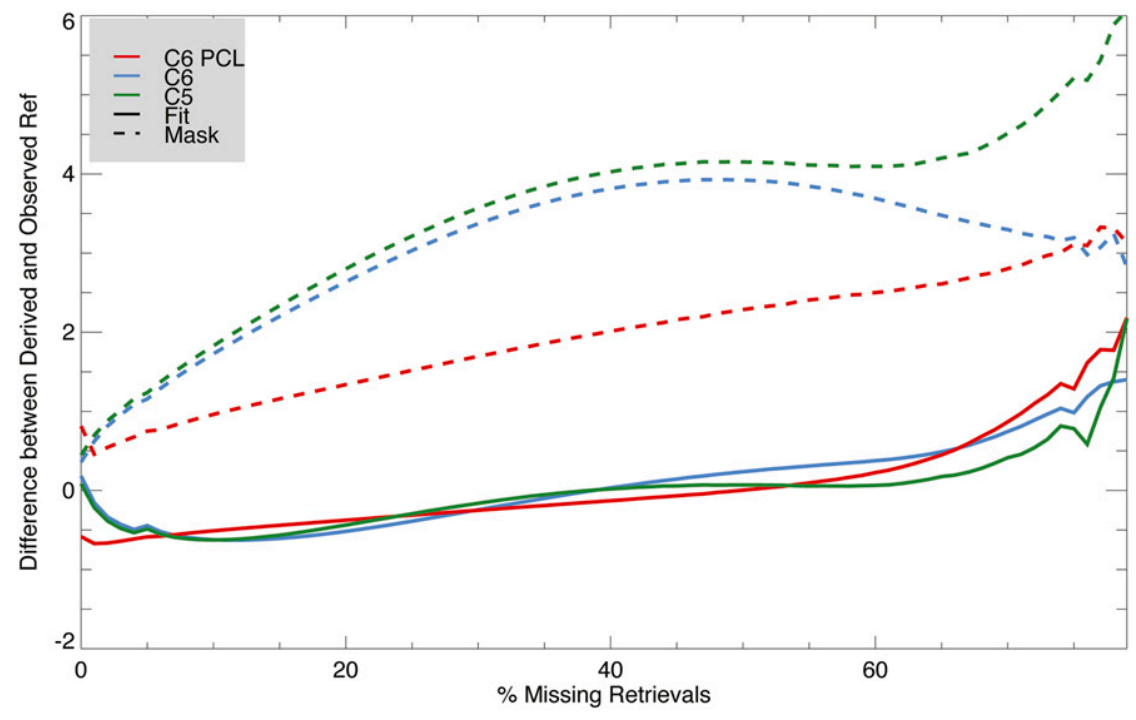

FIG. 3. The percentage of missing retrievals in comparison with the difference between the derived and observed visible reflectance for the fit (solid) and mask (dashed) methods for collection 5 (green), collection 6 (blue), and collection 6 PCL (red) for Aqua.

variables may introduce sensitivity into the fit method. This section seeks to diagnose the characteristics of when the fit method shows the most success recreating the scene visible reflectance as based on analysis of cloud fraction, viewing geometry, and cloud heterogeneity, which have relationships with 3D radiative cloud effects as well as the effects of the number of missing retrievals of liquid water path.

Using a 3D histogram allows us to examine the sensitivities of multiple variables at once. Figure 4 shows scattering zenith angle on the $x$ axis, cloud heterogeneity on the $y$ axis, and cloud fraction on the vertical $z$ axis. The cubes are a measure of the bias between the fitderived visible reflectance and the observed visible reflectance. For instance, looking at Aqua in the Northern Hemisphere from December to February (DJF), a cube with a scattering zenith angle of $50^{\circ}-68^{\circ}$, a heterogeneity of $0.7-0.9$, and a cloud fraction of $0.2-0.4$ has a bias of approximately -4 . The histograms were split up into Northern and Southern Hemispheres to analyze any seasonal sensitivity. These histograms were made for an array of different variables, but for brevity this analysis will focus on the relationship among scattering zenith angle, cloud heterogeneity, and cloud fraction. The histograms shown here use collection 6 PCL and showed patterns that are similar to those of collection 6 (no PCL) and collection 5.

Used in this analysis, cloud heterogeneity is a metric that is defined as the standard deviation of the visible reflectance in a scene divided by the mean visible reflectance to give a measure of the heterogeneity of the cloud scene (Liang et al. 2009). A high value indicates a heterogeneous cloud field, and a low value indicates a more homogeneous cloud field.

With the combination of cloud heterogeneity, scattering zenith angle, and cloud fraction, Aqua shows seasonality between the Northern and Southern Hemispheres (Fig. 4). The hemispheric summer months observe greater biases than do the hemispheric winter months, similar to the monthly biases explored in Fig. 1. Both hemispheres show a negative bias for areas with cloud fractions below 0.4 , corresponding to scenes with midrange cloud heterogeneity and smaller scattering angles. Positive biases are shown for overcast scenes with higher scattering angles with a tendency to be either completely homogeneous or heterogeneous. The smallest biases are shown for partially cloudy scenes (0.4-0.8) and midrange heterogeneity (0.3-0.9), with no strong dependence on the scattering angle.

The primary trend in the 3D histograms was the dependence on cloud fraction. There is a negative bias for scenes with lower cloud fraction, meaning the fit method is underestimating the observed visible reflectance. This would suggest that the distribution of liquid water path is skewed toward small values of liquid water path or that the calculated cloud fraction of the scene is too small. At lower cloud fractions, it is possible that there are fewer points available to calculate the ideal coefficients for a fit function between the observed optical depth and corresponding visible reflectance. Further exploration has shown that the differences at these lower cloud fractions are associated with large differences between 

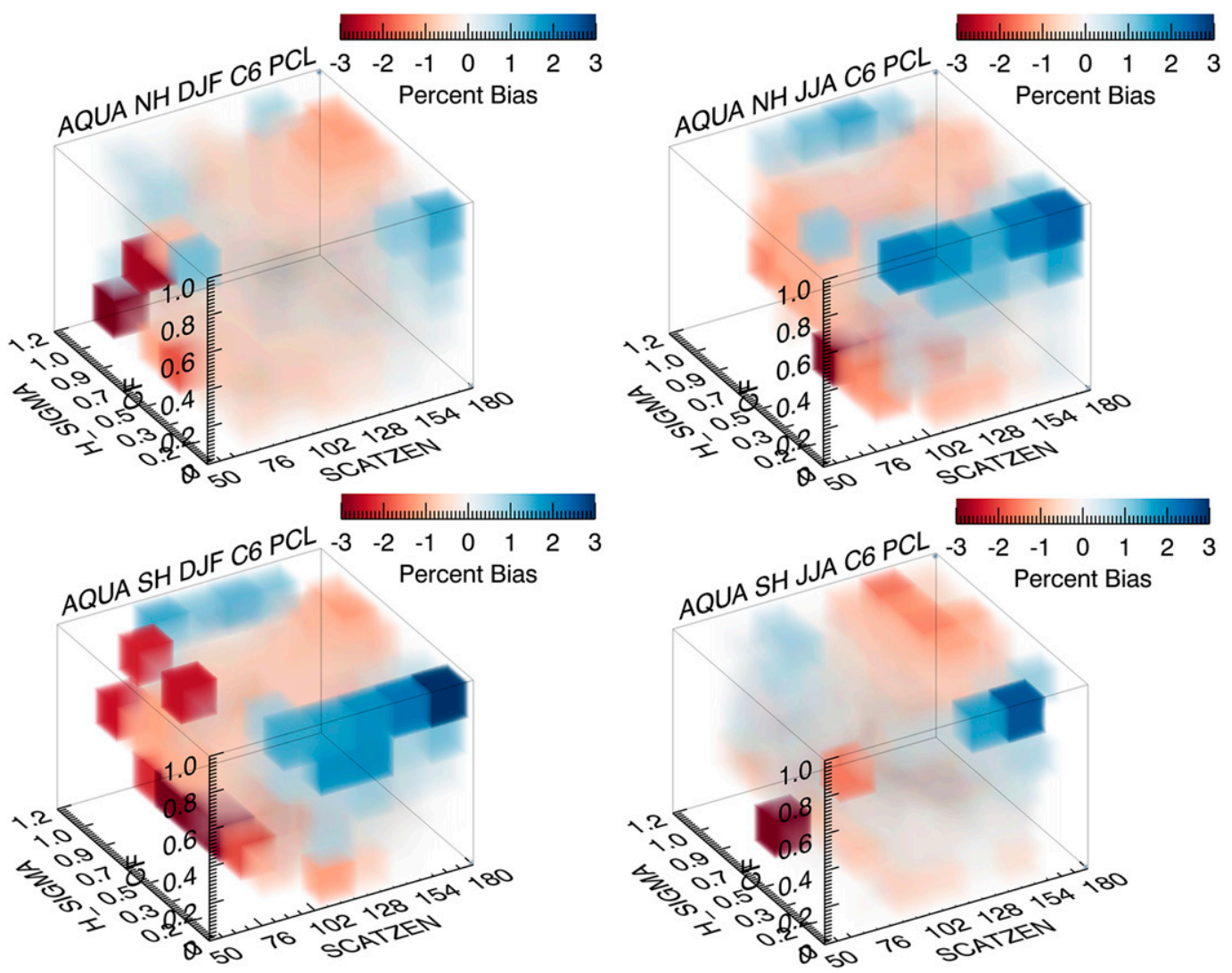

FIG. 4. 3D histograms showing bias between fit-derived reflectance and observed visible reflectance with respect to sensor zenith angle ( $x$ axis), cloud heterogeneity ( $y$ axis), and cloud fraction ( $z$ axis) for Aqua (left) DJF and (right) JJA in the (top) Northern and (bottom) Southern Hemispheres.

the mask-derived and fit-derived cloud fractions, which can be attributed to the derivation of clear and cloudy sky. These scenes tend to show a breakdown in the method during the separation of the clear and cloudy portions of the visible reflectance. Most scenes that were tested showed the clear-sky area of the visible reflectance to be approximately Gaussian, but there are certainly situations in which this is not the case (Gorroño et al. 2016). At this point in time, the fit method is currently constrained to using the Gaussian distribution, although future work includes finding a viable solution to consider other ways to distinguish between the clear and cloudy portions of the visible-reflectance distribution. To eliminate that negative bias, it is suggested to filter out scenes for which the difference between the mask- and fit-derived cloud fractions is greater than 0.2.

With the incorporation of the cloud-scene heterogeneity, the scenes with higher cloud fraction tend to have a positive bias for certain cloud heterogeneities. For the summer months, this was observed for both high and low cloud heterogeneity. The winter months only showed positive bias for high cloud heterogeneity. This means that scenes with overcast skies are overestimated by the fit method, which implies that these scenes may not benefit as heavily from using the fit method. The effects of viewing geometry were primarily seen at scenes with lower cloud fractions, with larger bias coinciding with smaller scattering angles. Many of the points closest to nadir were screened out because of the effect of sun glint over water, which makes it difficult to assess the success of the fit method for these angles.

Overall, there seemed to be minimal biases for scenes with midlevel cloud fractions between 0.2 and 0.8 along with heterogeneities varying from 0.2 to 1.0 . These scenes did not show a large dependence on viewing angle aside from a slight increase in the negative bias for the summer months for lower scattering angles.

\section{c. Liquid water path validation with AMSR-2}

Passive microwave sensors and passive multispectral imagers are often compared since they each use different physical mechanisms to derive cloud liquid water path. The comparison between these two instruments is important because they have different limitations to using them. Multispectral imagers are subject to scattering effects and dependence on drop size distributions, 


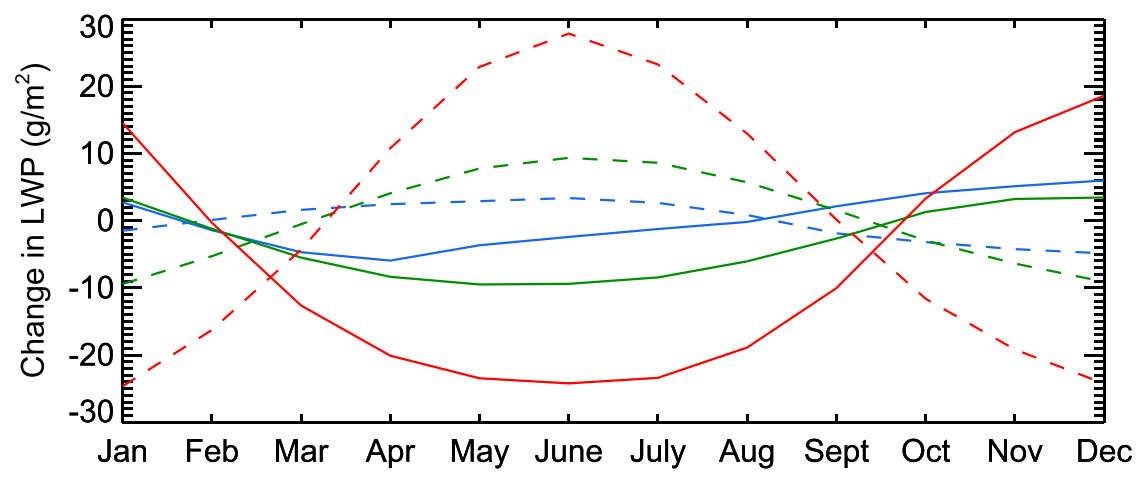

FIG. 5. Seasonal variations in liquid water path for AMSR-2 (blue), the MODIS fit method (green), and the MODIS mask method (red) for the Northern Hemisphere (solid) and the Southern Hemisphere (dashed) for 2013.

whereas microwave sensors are subject to uncertainties such as sea surface and cloud temperatures, surface emissivity, and precipitation. Comparison studies of these two sensors are important to climate studies and model validation (Bennartz 2007; Greenwald 2009; Seethala and Horváth 2010). Here, the fit- and maskderived liquid water paths are compared with AMSR-2 for 2013 , where the data are averaged over a $1^{\circ} \times 1^{\circ}$ area.

Given that it is hard to distinguish the differences in liquid water path on the basis of the biases and sensitivities introduced by each instrument, the seasonal cycles of liquid water path are compared. Figure 5 shows the seasonal cycle of liquid water path normalized by the global mean for each hemisphere, comparing the MODIS fit- and mask-derived liquid water paths with the GCOM-W1 AMSR-2 liquid water path. Similar to Fig. 1, the mask liquid water path shows a much stronger seasonal cycle than the fit liquid water path. The magnitude of the fit liquid water path seasonal cycle is in closer alignment with the AMSR-2 seasonal cycle for both the Northern and Southern Hemispheres. AMSR-2 shows a standard deviation of 4.52 and $3.19 \mathrm{~g} \mathrm{~m}^{-2}$ for the Northern and Southern Hemispheres, whereas the MODIS fit liquid water path has a standard deviation of 5.7 and $7.3 \mathrm{~g} \mathrm{~m}^{-2}$. The MODIS mask liquid water path has a seasonal cycle standard deviation of 17.34 and $20.88 \mathrm{~g} \mathrm{~m}^{-2}$ for the Northern and Southern Hemispheres. The fit method brings the magnitude of the seasonal cycle more into alignment with the AMSR-2 data in comparison with the mask data.

\section{Applications of the fit method}

\section{a. Satellite intercomparison}

An advantage of using this method is that it can be applied to any satellite dataset that provides measurements of visible reflectance and cloud optical properties, which allows for satellite comparison as well as applications of different cloud-processing algorithms. Here, the method is applied to two different instruments, MODIS and AVHRR, and two different types of cloud processing, standard MODIS processing and PATMOS-x. The main difference between the MODIS measurements and the PATMOS- $x$-processed AVHRR measurements is that PATMOS-x does not include any pixel filtering in the processing of cloud products, although there are physical circumstances in which the optical retrieval algorithm fails to converge and return a value. NOAA-18, which contains the AVHRR instrument, has the closest equatorial overpass time and overlapping years to Aqua. PATMOS-x/NOAA-18 and MODIS/ Aqua are compared for 2013 (Fig. 6).

The percent change is calculated for the liquid water path of PATMOS-x and MODIS using both the fit method and the mask method. The fit method-derived mean liquid water path shows a smaller difference between the two datasets in comparison with the mask method. The MODIS liquid water path tends always to be larger than the PATMOS-x liquid water path. The fit method shows the smallest changes between the two datasets along the marine stratocumulus regions off the coasts of California, Peru, and Angola. When simply comparing the mean liquid water path for PATMOS-x and MODIS, there are large differences, especially around the ITCZ and midlatitudes. For the fit method, the ITCZ region still shows the largest differences between the PATMOS-x and MODIS data, but the differences in the midlatitude liquid water path values have become much smaller.

Two-dimensional histograms comparing the mean liquid water path show more linearity of the fit method between MODIS and PATMOS-x in comparison with the mask method. The fit data also bring the data closer to a 1-to-1 relationship. The bias calculated for the mask 

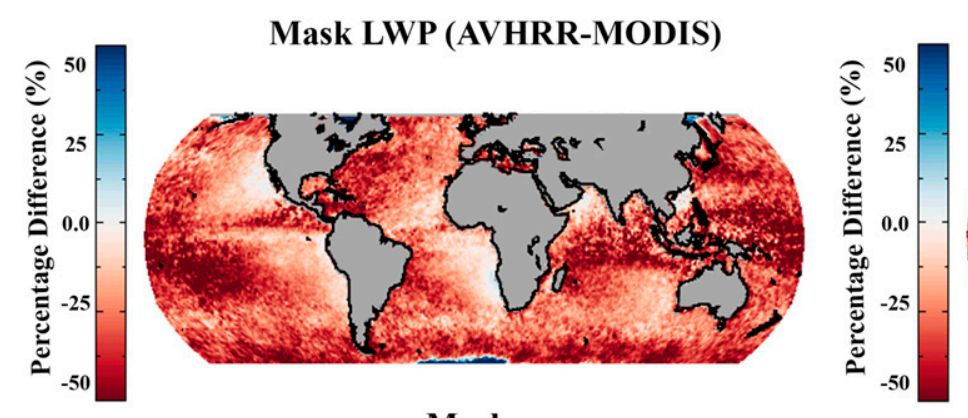

Fit LWP (AVHRR-MODIS)
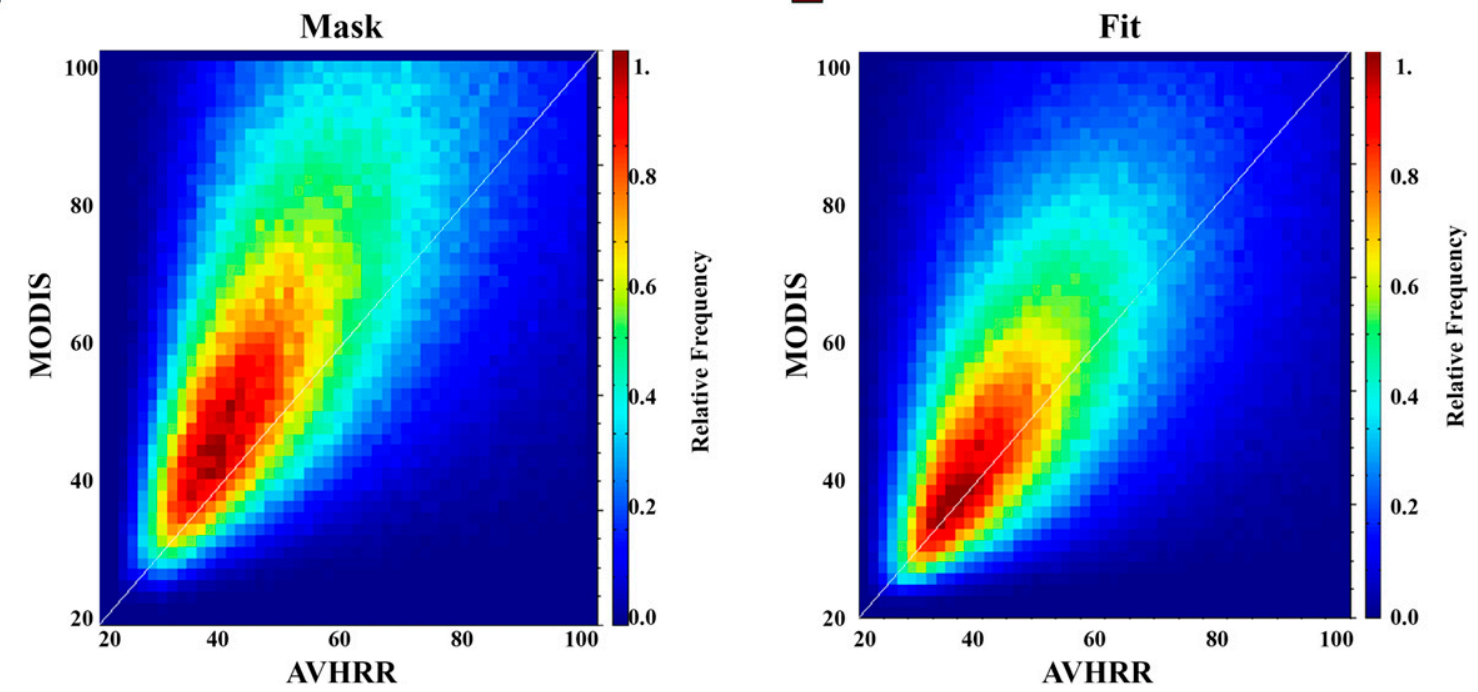

FIG. 6. For (left) the mask method and (right) the fit method for 2013, a satellite intercomparison between MODIS Aqua and PATMOS-x $N O A A-18$ AVHRR showing (top) the percentage difference for the liquid water path and (bottom) 2D histograms of the relative frequency of occurrence for the liquid water path.

method is equal to $27 \%$, whereas the fit method reduces the bias to $14.3 \%$. This application of the fit method to two satellite datasets brings the mean liquid water paths closer together, indicating that the restored missing retrievals of liquid water path add value to the datasets.

\section{b. Radiative transfer}

Another application of this method is its use in radiative transfer modeling. The fit method can be applied to improve the relationship between model output and the satellite data. Here, a radiative transfer model is used to identify radiative differences between the distributions of liquid water path applying the fit method. Using the I3RC Monte Carlo model, model input is created using MODIS data and applying the fit and mask methods as described in section 2. Two scenes are used to explore the utility of the fit method. The scenes for which the full distributions of liquid cloud properties are used are referred to as 3D fit and 3D mask. For this application, a year of the MODIS level-2B data over a $20^{\circ} \times 30^{\circ}$ area over the South Pacific is sampled and run through the model to generate albedo values. Approximately 50 scenes per day are sampled.
The application of the 3D Monte Carlo model using the fit and mask methods shows that changes in albedo occur when altering the distributions of liquid water path to include possibly missed retrievals. Figure 7 shows the albedo bias between the 3D fit and 3D mask over the South Pacific region for each season. The largest albedo bias occurs during June-August (JJA) over the southwestern portion of the scene, with a mean bias of 0.06 . The spring and autumn months show moderate mean albedo biases of 0.04 and 0.03 , respectively. DJF shows the lowest amount of bias, with a mean value of 0.02 . The seasonality of the albedo differences between the summer and winter months could correspond to the type of clouds observed in this region during each season. Over the South Pacific, cloud heterogeneity tends to be higher in JJA than in DJF. This suggests that the more heterogeneous types of clouds show the largest changes in albedo when the fit method is applied.

These biases in the derived albedo show that there is a change occurring when using mask- and fit-derived distributions of liquid water path in each scene. Because of the large $0.1^{\circ}$ sampling, full $3 \mathrm{D}$ effects such as the 

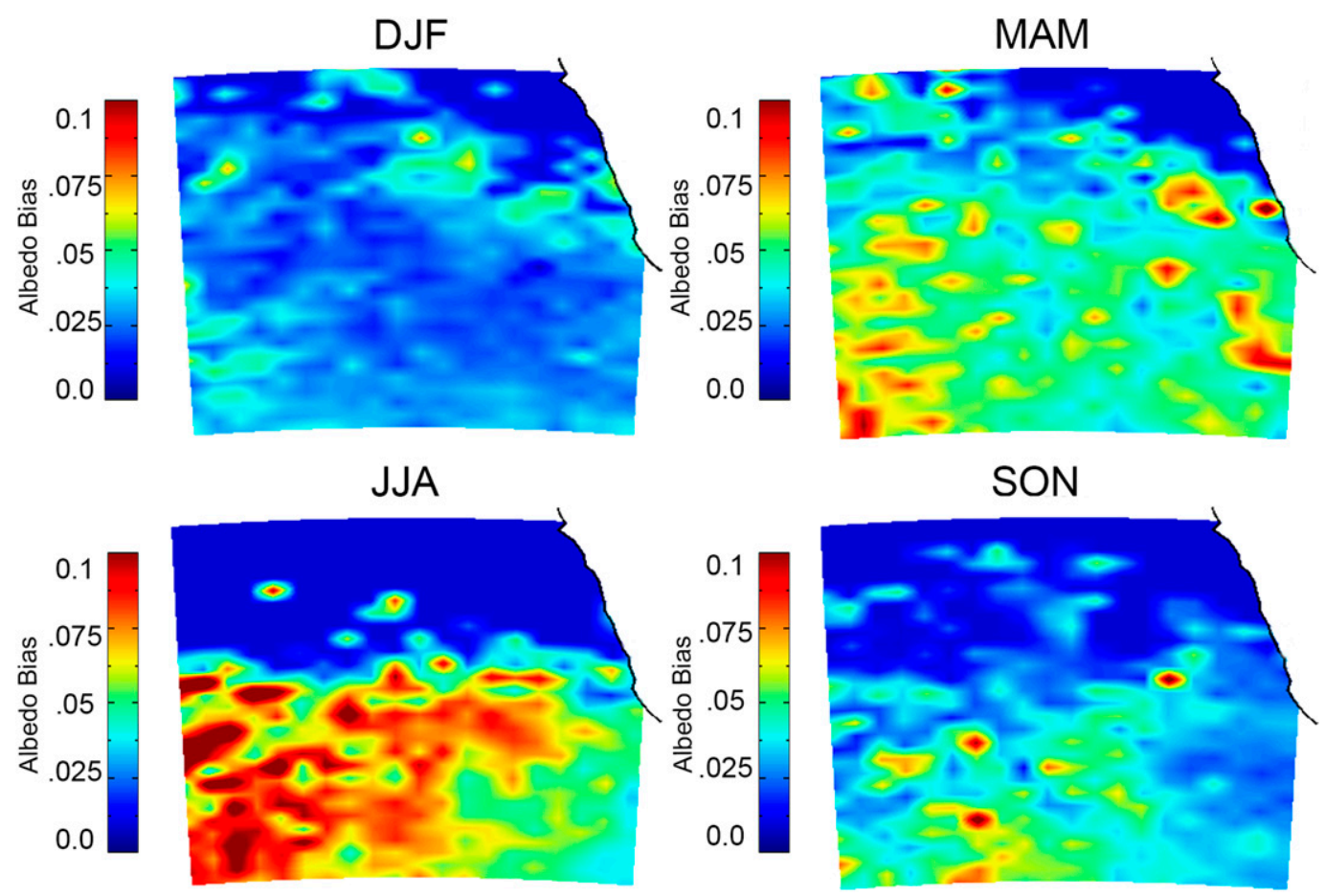

FIG. 7. The albedo bias between the 3D fit-derived and 3D mask-derived albedos for each season of 2008 over a $20^{\circ} \times 30^{\circ}$ region in the South Pacific Ocean.

horizontal transport of photons between grid cells are not observed, and results can be similarly computed from a 1D radiative transfer model (Marshak et al. 1995). Future work seeks to apply the fit method to a range of smaller grid sizes and regions to analyze the $3 \mathrm{D}$ radiative effects as well as to expand the calculations to include intensity and surface-heating rates.

\section{Discussion and conclusions}

The effects of internal heterogeneity were explored by the application of the fit method used to create horizontal distributions of cloud properties over a $1^{\circ} \times 1^{\circ}$ area and were assessed by how well the method could recreate the observed visible reflectance using the MODIS instrument on Aqua from 2003 to 2014. This included a comparison of MODIS collection 5, collection 6 , and collection 6 with partly cloudy pixels. When recreating the visible reflectance, the mask method continually overestimated for all datasets, with biases ranging from 0.75 to 4.6. The mask method showed a seasonal cycle, with the largest overestimation occurring during the hemispheric summers for collection 5 and collection 6 . Collection 6 with PCL pixels reduced the bias and seasonal cycle of the mask method. The fit method tends to slightly underestimate the observed visible reflectance, with biases ranging from -0.74 to -0.1 . Utilization of the fit method showed global improvement relative to the mask method. Collection 5 showed the most improvement using the fit method, with improvements up to $7 \%$. Collection 6 also benefited from the use of the fit method, with improvements up to $5 \%$. When the partly cloudy pixels were added to the collection- 6 data, the mask bias was greatly minimized, and the fit bias remained relatively constant in comparison with the other datasets.

Adding the partly cloudy pixels to collection 6 adds value when parameterizing distributions of cloud properties. The stratocumulus regions off the coast of California, Peru, and Angola were notable areas where the least amount of improvement occurred, likely because of their homogeneous structure. An analysis of the number of missing cloud-property retrievals in a scene shows that the fit method performs the best when $20 \%-70 \%$ of retrievals are missing. This fit method is capable of restoring the missing retrievals and maintaining the scene visible reflectance.

Three-dimensional histograms were used to determine sensitivities of the fit method with respect to cloud fraction, cloud heterogeneity, and viewing geometry. From a seasonal perspective, the hemispheric summers tended to show larger biases. An underestimation of the visible reflectance was seen in scenes with low cloud fraction. Cloud heterogeneity showed the largest effect 
on overcast scenes. There was a positive bias for both high and low values of the cloud heterogeneity index. The effects of viewing geometries showed a negative bias for low cloud fraction, increasing in magnitude as the angles become closer to nadir. The fit method did not show much sensitivity to scenes with medium amounts of cloud fraction and midvalue cloud heterogeneity index, which means the application of the fit method would help these scenes the most. The Gaussian assumption of clear sky is subject to causing biases for scenes with lower cloud fraction values. There is currently no viable way to change the distribution that the fit method uses to separate clear sky from cloudy sky, but future work includes seeking out a way to fix this problem.

The fit method also shows its utility in the comparison with other satellite datasets. A comparison of the seasonal cycle of liquid water path shows that the fit method generates a seasonal cycle that is closer to the GCOM-W1 AMSR-2 satellite than is that generated by the mask method. A satellite intercomparison was also conducted since the fit method can be applied to any dataset that contains both cloud-property retrievals and visiblereflectance measurements. The PATMOS-x processing was used on NOAA-18, which, unlike MODIS, does not perform pixel filtering within its algorithms. The fit method was applied to PATMOS-x and MODIS. When compared with the mask method, the fit method showed a stronger relationship and more linear fit between the derived liquid water path values.

Another application of the fit method is the ability to incorporate the adjusted distributions of liquid cloud properties into a radiative transfer model. The I3RC Monte Carlo model is used to apply the fit and mask methods to 3D Monte Carlo radiative transfer simulations to 1 year of MODIS data over the South Pacific. Overall, the albedo bias between the fit and mask methods was the highest during the Southern Hemisphere winter. The albedo bias between the seasons ranged from 0.02 to 0.06 . The grid size is a factor that influences the horizontal transport of photons, and therefore future work seeks to study the impact of 3D effects with the fit method by varying the grid size.

The applications of this method serve to diminish the bias of internal heterogeneity within GCMs and to add value to parameterizations of cloud properties. The variable dependencies and spatial analysis show that external heterogeneity also plays a role in the relationship of cloud properties and visible reflectance. Ongoing work aims to incorporate the fit method and metrics for identifying external heterogeneity into a 3D radiative transfer model. The goal of this work will be to identify the radiative bias contributed by the sources of internal and external heterogeneity on the MODIS dataset. This value-added MODIS maritime cloud liquid water climatology will be publicly available online (ftp.ssec.wisc. edu/pub/modis_value_added/).

Acknowledgments. This research is supported by NASA New (Early Career) Investigator Program in Earth Science: Grant NNX12AL95G.

\section{REFERENCES}

Ackerman, S. A., K. I. Strabala, W. P. Menzel, R. A. Frey, C. C. Moeller, and L. E. Gumley, 1998: Discriminating clear sky from clouds with MODIS. J. Geophys. Res., 103, 3214132 157, doi:10.1029/1998JD200032.

_ , R. Frey, K. Strabala, Y. Liu, L. Gumley, B. Baum, and P. Menzel, 2010: Discriminating clear-sky from cloud with MODIS-Algorithm theoretical basis document (MOD35). Cooperative Institute for Meteorological Satellite Studies Tech. Rep., 121 pp. [Available online at https://modis-atmos. gsfc.nasa.gov/_docs/MOD35_ATBD_Collection6.pdf.]

Barker, H. W., and P. Räisänen, 2005: Radiative sensitivities for cloud structural properties that are unresolved by conventional GCMs. Quart. J. Roy. Meteor. Soc., 131, 3103-3122, doi:10.1256/qj.04.174.

_ B. A. Wiellicki, and L. Parker, 1996: A parameterization for computing grid-averaged solar fluxes for inhomogeneous marine boundary layer clouds. Part II: Validation using satellite data. J. Atmos. Sci., 53, 2304-2316, doi:10.1175/ 1520-0469(1996)053<2304:APFCGA>2.0.CO;2.

, G. L. Stephens, and Q. Fu, 1999: The sensitivity of domainaveraged solar fluxes to assumptions about cloud geometry. Quart. J. Roy. Meteor. Soc., 125, 2127-2152, doi:10.1002/ qj.49712555810.

_, and Coauthors, 2003: Assessing 1D atmospheric solar radiative transfer models: Interpretation and handling of unresolved clouds. J. Climate, 16, 2676-2699, doi:10.1175/ 1520-0442(2003)016<2676:ADASRT>2.0.CO;2.

_ J. N. Cole, J. Li, and K. von Salzen, 2016: A parameterization of 3-D subgrid-scale clouds for conventional GCMs: Assessment using A-Train satellite data and solar radiative transfer characteristics. J. Adv. Model. Earth Syst., 8, 566-597, doi:10.1002/2015MS000601.

Bennartz, R., 2007: Global assessment of marine boundary layer cloud droplet number concentration from satellite. J. Geophys. Res., 112, D02201, doi:10.1029/2006JD007547.

Bogenschutz, P. A., and S. K. Krueger, 2013: A simplified PDF parameterization of subgrid-scale clouds and turbulence for cloud-resolving models. J. Adv. Model. Earth Syst., 5, 195-211, doi:10.1002/jame.20018.

Cahalan, R. F., W. Ridgway, W. J. Wiscombe, T. L. Bell, and J. B. Snider, 1994a: The albedo of fractal stratocumulus clouds. J. Atmos. Sci., 51, 2434-2455, doi:10.1175/ 1520-0469(1994)051<2434:TAOFSC > 2.0.CO;2.

,,$--\longrightarrow$, and S. Gollmer, 1994b: Independent pixel and Monte Carlo estimates of stratocumulus albedo. J. Atmos. Sci., 51, 3776-3790, doi:10.1175/1520-0469(1994)051<3776: IPAMCE > 2.0.CO;2.

, and Coauthors, 2005: The I3RC: Bringing together the most advanced radiative transfer tools for cloudy atmospheres. Bull. Amer. Meteor. Soc., 86, 1275-1293, doi:10.1175/ BAMS-86-9-1275. 
Cho, H. M., and Coauthors, 2015: Frequency and causes of failed MODIS cloud property retrievals for liquid phase clouds over global oceans. J. Geophys. Res. Atmos., 120, 4132-4154, doi:10.1002/2015JD023161.

Di Giuseppe, F., and A. M. Tompkins, 2003: Effect of spatial organization on solar radiative transfer in three-dimensional idealized stratocumulus cloud fields. J. Atmos. Sci., 60, 1774-1794, doi:10.1175/1520-0469(2003)060<1774:EOSOOS > 2.0.CO;2.

$\longrightarrow$, and — 2005: Impact of cloud cover on solar radiative biases in deep convective regimes. J. Atmos. Sci., 62, 19892000, doi:10.1175/JAS3442.1.

Foster, M. J., R. Bennartz, and A. Heidinger, 2011: Estimation of liquid cloud properties that conserve total-scene reflectance using satellite measurements. J. Appl. Meteor. Climatol., 50, 96-109, doi:10.1175/2010JAMC2456.1.

Fu, Q., B. Carlin, and G. Mace, 2000: Cirrus horizontal inhomogeneity and OLR bias. Geophys. Res. Lett., 27, 33413344, doi:10.1029/2000GL011944.

Gorroño, J., A. Bialek, P. D. Green, P. Harris, T. Scanlon, N. P. Fox, and C. Underwood, 2016: Non-normal distribution of the top-of-atmosphere satellite optical measurements over calibration sites. Int. J. Remote Sens., 37, 4665-4682, doi:10.1080/ 01431161.2016.1220030.

Greenwald, T. J., 2009: A 2 year comparison of AMSR-E and MODIS cloud liquid water path observations. Geophys. Res. Lett., 36, L20805, doi:10.1029/2009GL040394.

Heidinger, A. K., 2003: Rapid daytime estimation of cloud properties over a large area from radiance distributions. J. Atmos. Oceanic Technol., 20, 1237-1250, doi:10.1175/ 1520-0426(2003)020<1237:RDEOCP $>2.0 . C O ; 2$.

- M. J. Foster, A. Walther, and X. Zhao, 2014: The Pathfinder Atmospheres-Extended AVHRR climate dataset. Bull. Amer. Meteor. Soc., 95, 909-922, doi:10.1175/BAMS-D-12-00246.1.

Herwehe, J. A., K. Alapaty, T. L. Spero, and C. G. Nolte, 2014: Increasing the credibility of regional climate simulations by introducing subgrid-scale cloud-radiation interactions. J. Geophys. Res. Atmos., 119, 5317-5330, doi:10.1002/2014JD021504.

IPCC, 2013: Climate Change 2013: The Physical Science Basis. Cambridge University Press, 1535 pp., doi:10.1017/ CBO9781107415324.

King, M. D., S.-C. Tsay, S. E. Platnick, M. Wang, and K.-N. Liou, 1997: Cloud retrieval algorithms for MODIS: Optical thickness, effective particle radius, and thermodynamic phase. NASA Goddard Space Flight Center MODIS Algorithm Theoretical Basis Doc. ATBD-MOD-05, 79 pp. [Available online at https://eospso.nasa.gov/sites/default/files/atbd/atbd_ mod05.pdf.]

, S. Platnick, P. A. Hubanks, G. T. Arnold, E. G. Moody, G. Wind, and B. Wind, 2006: Collection 005 change summary for the MODIS cloud optical property (06_OD) algorithm. NASA Goddard Space Flight Center Collection 005 Change Summary Doc., 23 pp. [Available online at https://modis-atmos.gsfc.nasa. gov/C005_Changes/C005_CloudOpticalProperties_ver311.pdf.] , - W. P. Menzel, S. A. Ackerman, and P. A. Hubanks, 2013: Spatial and temporal distribution of clouds observed by MODIS onboard the Terra and Aqua satellites. IEEE Trans. Geosci. Remote Sens., 51, 3826-3852, doi:10.1109/ TGRS.2012.2227333.

Koren, I., L. Oreopoulos, G. Feingold, L. A. Remer, and O. Altaratz, 2008: How small is a small cloud? Atmos. Chem. Phys., 8, 3855-3864, doi:10.5194/acp-8-3855-2008.

Larson, V. E., R. Wood, P. R. Field, J.-C. Golaz, T. H. Vonder Haar, and W. R. Cotton, 2001: Systematic biases in the microphysics and thermodynamics of numerical models that ignore subgrid-scale variability. J. Atmos. Sci., 58, 1117-1128, doi:10.1175/1520-0469(2001)058<1117:SBITMA > 2.0.CO;2.

Liang, L., L. Di Girolamo, and S. Platnick, 2009: View-angle consistency in reflectance, optical thickness and spherical albedo of marine water-clouds over the northeastern Pacific through MISR-MODIS fusion. Geophys. Res. Lett., 36, L09811, doi:10.1029/2008GL037124.

Lu, M. L., and J. H. Seinfeld, 2006: Effect of aerosol number concentration on cloud droplet dispersion: A large-eddy simulation study and implications for aerosol indirect forcing. J. Geophys. Res., 111, D02207, doi:10.1029/2005JD006419.

Marshak, A., A. Davis, W. Wiscombe, and R. Cahalan, 1995: Radiative smoothing in fractal clouds. J. Geophys. Res., 100, 26247-26261, doi:10.1029/95JD02895.

—,,,-- W. Ridgway, and R. Cahalan, 1998: Biases in shortwave column absorption in the presence of fractal clouds. J. Climate, 11, 431-446, doi:10.1175/1520-0442(1998)011<0431: BISCAI>2.0.CO;2.

Oreopoulos, L., and R. Davies, 1998: Plane parallel albedo biases from satellite observations. Part II: Parameterizations for bias removal. J. Climate, 11, 933-944, doi:10.1175/ 1520-0442(1998)011<0933:PPABFS > 2.0.CO;2.

_ M. D. Chou, M. Khairoutdinov, H. W. Barker, and R. F. Cahalan, 2004: Performance of Goddard Earth Observing System GCM column radiation models under heterogeneous cloud conditions. Atmos. Res., 72, 365-382, doi:10.1016/ j.atmosres.2004.03.025.

_ _ R. F. Cahalan, and S. Platnick, 2007: The plane-parallel albedo bias of liquid clouds from MODIS observations. J. Climate, 20, 5114-5125, doi:10.1175/JCLI4305.1.

Pincus, R., and S. A. Klein, 2000: Unresolved spatial variability and microphysical process rates in large-scale models. J. Geophys. Res., 105, 27 059-27 065, doi:10.1029/2000JD900504.

_ , and K. F. Evans, 2009: Computational cost and accuracy in calculating three-dimensional radiative transfer: Results for new implementations of Monte Carlo and SHDOM. J. Atmos. Sci., 66, 3131-3146, doi:10.1175/2009JAS3137.1.

__, S. A. McFarlane, and S. A. Klein, 1999: Albedo bias and the horizontal variability of clouds in subtropical marine boundary layers: Observations from ships and satellites. J. Geophys. Res., 104, 6183-6191, doi:10.1029/ 1998JD200125.

Platnick, S., and Coauthors, 2015: MODIS cloud optical properties: User guide for the collection 6 level-2 MOD06/MYD06 product and associated level-3 datasets. NASA Goddard Space Flight Center Rep., 141 pp. [Available online at http:// modis-atmos.gsfc.nasa.gov/_docs/C6MOD06OPUserGuide. pdf.]

Räisänen, P., H. W. Barker, M. F. Khairoutdinov, J. Li, and D. A. Randall, 2004: Stochastic generation of subgrid-scale cloudy columns for large-scale models. Quart. J. Roy. Meteor. Soc., 130, 2047-2067, doi:10.1256/qj.03.99.

Seethala, C., and Á. Horváth, 2010: Global assessment of AMSR-E and MODIS cloud liquid water path retrievals in warm oceanic clouds. J. Geophys. Res., 115, D13202, doi:10.1029/ 2009JD012662.

Shonk, J. K., R. J. Hogan, and J. Manners, 2012: Impact of improved representation of horizontal and vertical cloud structure in a climate model. Climate Dyn., 38, 2365-2376, doi:10.1007/s00382-011-1174-2.

Siebesma, A. P., and Coauthors, 2003: A large eddy simulation intercomparison study of shallow cumulus convection. $J$. 
Atmos. Sci., 60, 1201-1219, doi:10.1175/1520-0469(2003)60<1201: ALESIS $>2.0 . \mathrm{CO} ; 2$.

Stevens, B., and Coauthors, 2005: Evaluation of large-eddy simulations via observations of nocturnal marine stratocumulus. Mon. Wea. Rev., 133, 1443-1462, doi:10.1175/MWR2930.1.

Webb, M. J., F. H. Lambert, and J. M. Gregory, 2013: Origins of differences in climate sensitivity, forcing and feedback in climate models. Climate Dyn., 40, 677-707, doi:10.1007/ s00382-012-1336-x.
Xiao, H., W. I. Gustafson Jr., and H. Wang, 2014: Impact of subgridscale radiative heating variability on the stratocumulus-to-trade cumulus transition in climate models. J. Geophys. Res. Atmos., 119, 4192-4203, doi:10.1002/2013JD020999.

Zhang, Z., A. S. Ackerman, G. Feingold, S. Platnick, R. Pincus, and H. Xue, 2012: Effects of cloud horizontal inhomogeneity and drizzle on remote sensing of cloud droplet effective radius: Case studies based on large-eddy simulations. J. Geophys. Res., 117, D19208, doi:10.1029/2012JD017655. 